\title{
Immunomodulatory Effects of the Tityus serrulatus Venom on Murine Macrophage Functions in Vitro
}

\author{
Vera L. Petricevich ${ }^{1,2}$ and Ivo Lebrun ${ }^{3}$ \\ ${ }^{1}$ Facultad de Medicina de la Universidad Autonoma del Estado de Morelos, 62210 Cuernavaca, Mexico \\ ${ }^{2}$ Immunochemistry Laboratory, Butantan Institute, 055503-900 São Paulo, Brazil \\ ${ }^{3}$ Biochemistry and Biophysics Laboratory, Butantan Institute, 055503-900 São Paulo, Brazil
}

Received 27 September 2004; accepted 29 October 2004

\begin{abstract}
Tityus serrulatus scorpion venom (TSV) consists of a very complex mixture of molecules and demonstrates significant immunomodulatory activities capable of stimulating immune functions in vivo. The purpose of this study was to compare the crude TSV with fractionated toxins extracted from this venom in order to determine which toxin(s) presented immunomodulatory effects on peritoneal macrophages. TSV was fractionated using gel filtration chromatography resulting in 5 heterogeneous fractions. The effects of these different fractions were analysed in vitro using detection by means of cytokines, oxygen intermediate metabolites $\left(\mathrm{H}_{2} \mathrm{O}_{2}\right)$, and nitric oxide (NO) in supernatants of peritoneal macrophages. Several functional bioassays were employed: tumor necrosis factor (TNF) activity was assayed by measuring its cytotoxic activity in L929 cells, and other cytokines were assayed by enzyme-linked immunosorbent assay, whereas NO levels were detected by Griess colorimetric reactions in culture supernatant of macrophages exposed to different fractions. In vitro studies revealed that all fractions studied here presented an increment in $\mathrm{H}_{2} \mathrm{O}_{2}, \mathrm{NO}$, and cytokines levels. The more pronounced increments were observed in macrophage cultures exposed to fraction FII which demonstrated that (a) the highest levels of IL- $1 \alpha$, IL- $\beta$, and TNF were observed after 12 hours and that (b) the maximum levels of IFN- $\gamma$ and NO were observed after 72 hours. Taken together, these data indicate that fractions have a differential immunomodulating effect on macrophage secretion, and that FII is a potent activator of TNF production of macrophages.
\end{abstract}

\section{INTRODUCTION}

Scorpion venoms consist of a complex of several toxins that exhibit a wide range of biological properties and actions, as well as chemical compositions, toxicity, and pharmacokinetic and pharmacodynamic characteristics.

Tityus serrulatus is considered one of the most dangerous species to humans in Brazil and is responsible for many clinical cases of envenomation in the southern region of this country. This venom is capable of exerting a variety of effects on excitable tissues, due to its role in the peripheral nervous system where it enhances the release of neurotransmitters [1]. The information presented here deals with biological, chemical, and immunological aspects of different toxins and offers a comparison and an assessment of these, as observed in the symptoms presented in mice from the most dangerous species of Brazilian scorpions: T serrulatus. This species is found in an immense geographical area of the country and represents an important public health problem causing fatal accidents

Correspondence and reprint requests to Vera L. Petricevich, Facultad de Medicina de la Universidad Autonoma del Estado de Morelos, 62210 Cuernavaca, Mexico; velupetri@hotmail.com among humans $[2,3]$. The most thoroughly studied aspects consist of the isolation, chemical, and physiological characterization of these toxic peptides $[4,5,6]$.

Victims of envenoming by a scorpion suffer a variety of pathologies, involving mainly both sympathetic (tachycardia, hypertension, sweating, and mydriasis) and parasympathetic (bradycardia, hypotension, secretions, and miosis) stimulation as well as central manifestations such as irritability, hyperthermia, vomiting, tremor, and convulsion. Experimental studies have shown that the injection of whole venom and purified toxins from the venom $T$ serrulatus can cause profuse salivation [7], increased gastric [8] and pancreatic secretion [9], acute gastric mucosal $[10]$ and pancreatic $[1,9]$ injuries, as wells as disorders in intestinal motility [1]. In order to address these issues, basic information needs to be obtained from representative experiments on animal models using adequate venom samples as it is necessary to apply inflammatory inducers. Previous studies have shown that differential susceptibility to venom depends on the strain of mice used $[11,12]$. It is well established that the predominant lethal action of scorpion venom exerts a variety of effects on excitable tissues. In the case of snake venoms, it is well known that levels of lethality and toxicity exhibit enormous variety according to the age, sex, nutritional 
state, and geographic regions where the animals were captured [13]. To minimise the experimental bias, BALB/c mice and a mixture of $T$ serrulatus venom obtained from 40 adult specimens, all from the same geographic region, were used throughout all experiments.

Macrophages have been shown to be involved in different homeostatic mechanisms and pathological events, and may be engaged in complex interactions. Macrophages are involved in several areas of body function, such as phagocytosis, enzyme liberation, free radical generation, and as mediators of inflammatory processes. Cytokine release by macrophages has shown that excessive or insufficient production may significantly contribute to the pathophysiology of a range of diseases $[14,15,16,17]$. Generally, the treatment of macrophages with lead results in the disregulation of the production of inflammatory cytokines, tumor necrosis factor (TNF), interleukin1 (IL-1), and IL-6, and preferential production of the TH1 type of cytokines interferon-gamma (IFN- $\gamma$ ) and IL2 . In the case of crude scorpion venom, the treatment of macrophages results in the production of inflammatory cytokines [18]. It is widely acknowledged that in cytokines, a diverse group of proteins are important for the regulation of inflammatory responses as well as in the generation of immunity to pathogens. Interaction with venom causes the secretion of a variety of cytokines by macrophages. However a detailed description of the induction of these cytokines by venoms is still unclear even though various studies regarding cytokine induction by these toxins as well as by infection have been reported $[18,19]$.

TSV is involved in immunomodulation, although the mechanism for this activity has not been fully elucidated. This study was designed to determine the most important toxin obtained from venom which causes the immunomodulatory activity. Here for the first time we described in detail the effect of purified fractions extracted from TSV on the production of cytokines and nitric oxide (NO) production and on macrophage activation. Immunomodulatory effects induced by these fractions on NO production and macrophage activation were compared with those obtained from the cells stimulated with IFN- $\gamma$.

\section{MATERIALS AND METHODS}

\section{Chemicals, reagents, and buffers}

Actinomycin D, orthophenyldiamine (OPD), and nitric oxide (NO) were purchased from Sigma (St. Louis, Mo), fetal calf serum (FCS) and RPMI-1640 medium were purchased from Cultilab (Campinas, SP, Brazil), Sephadex G-50 Superfine was purchased from Pharmacia Fine Chemicals (Uppsala, Sweden), ANTI-mouse-IL-1 (clones ALF-1G1 and B122), recombinant IL-1, ANTI-mouseIL-6 (clones MP5-20F3 and MP5-32C11), recombinant IL-6, ANTI-mouse-IFN- $\gamma$ (clones XGM1.2 and R4-6A2) and recombinant IFN- $\gamma$ were purchased from BD Bio- sciences Pharmingen (Calif), and recombinant TNF was purchased from Boehringer Mannheim (Mannheim, Germany).

\section{Scorpion venom}

$T$ serrulatus scorpions were provided by the Artropodes Laboratory, Butantan Institute (SP, Brazil). The venom was obtained by electrostimulation using the method previously described [20]. Fifty mg of crude dried venom was solubilized in ammonium acetate buffer, $\mathrm{pH} 4.7$, and centrifuged at $15000 \mathrm{Xg}$ for 30 minutes, here named TSV $(-)$, without glycoproteins, and fraction G was named the nontoxic fraction. Soluble venom from $T$ serrulatus was applied to a Sephadex G-50 Superfine and eluted with $20 \mathrm{mM}$ ammonium acetate buffer, $\mathrm{pH} 4.7$. The fractions were collected using an automatic collector (Pharmacia-LKB Frac-100). Fractions were pooled according to the absorbance profile at $280 \mathrm{~nm}$ and assayed for toxicity. The five fractions obtained here are named as fractions FI, FII, FIII, FIV, and FV which correspond to $18.6 \%, 31.4 \%, 21.3 \%, 24.4 \%$, and $4.3 \%$, respectively.

\section{Animals}

$\mathrm{BALB} / \mathrm{c}$ female mice (18-20 g), obtained from the Butantan Institute, were used throughout the study to test the lethality of the venom and its components. Different fractions containing $50 \mu \mathrm{g}$ of protein diluted in the appropriate buffers were assayed by intraperitoneal (IP) injection. Intoxicated animals usually showed the following symptoms: tremor, salivation, diarrhoea, and death. Mice were maintained and used according to animal welfare international recommendations of the International Society on Toxicology, 1992 [21].

\section{Stimulation of mice peritoneal macrophages}

Groups of mice from BALB/c were sacrificed and their cells were harvested by peritoneal lavage [22]. The peritoneal cavity was injected with $5 \mathrm{~mL}$ of cold RPMI1640. The fluid-distended peritoneal cavity was massaged, and the cells were collected and washed three times by centrifugation at $290 \mathrm{Xg}$ for 5 minutes. The cells were seeded in 96-well microtiter plates at a concentration of $1 \times 10^{6}$ cells $/ \mathrm{mL}$ and cultured in RPMI-1640 medium supplemented with $10 \%$ FCS. After incubation at $37^{\circ} \mathrm{C}$ for 2 hours in humidified $5 \% \mathrm{CO}_{2}$, the plates were then washed twice with RPMI-1640 medium to remove nonadherent cells and the adherent cells were referred to as macrophages. More than $95 \%$ of the cells was identified as macrophages by morphology and also in terms of their ability of ingesting IgG-opsonised red cells [23]. These cells were exposed to different concentrations of fractions obtained from TSV venom in RPMI-1640 containing 10\% FCS. After incubation at $37^{\circ} \mathrm{C}$ for various intervals of time in a humidified atmosphere of $5 \% \mathrm{CO}_{2}$, the supernatants were collected and stored at $-20^{\circ} \mathrm{C}$ until assayed for the presence of $\mathrm{NO}$ and cytokines. 


\section{$\mathrm{H}_{2} \mathrm{O}_{2}$ determination}

Peritoneal macrophages were obtained as described previously where $1 \times 10^{6}$ cells $/ \mathrm{mL}$ was seeded and incubated in a volume of $100 \mu \mathrm{L}$ with no stimuli (control), or were exposed to recombinant IFN- $\gamma(10 \mathrm{ng} / \mathrm{mL})$ or fractions obtained from TSV of varying amounts $(\mu \mathrm{g} / \mathrm{mL})$. After incubation at $37^{\circ} \mathrm{C}$ for various intervals of time in a humidified atmosphere of $5 \% \mathrm{CO}_{2}$, the supernatants were then collected for $\mathrm{NO}$ determination and $100 \mu \mathrm{L}$ of red phenol solution containing $140 \mathrm{mM} \mathrm{NaCl}$, $10 \mathrm{mM} \mathrm{K}_{2} \mathrm{PO}_{4}, 5.5 \mathrm{mM}$ dextrose, and $5.5 \mathrm{mM}$ horseradish peroxidase were added to the adherent cells for $\mathrm{H}_{2} \mathrm{O}_{2}$ determination. After incubation for 1 hour at $37^{\circ} \mathrm{C}, 10 \mu \mathrm{L}$ of $1 \mathrm{M} \mathrm{NaOH}$ were added and the absorbances were measured at $620 \mathrm{~nm}$, using an automatic enzyme immunoassay reader [24].

\section{NO determination}

The levels of NO in supernatants taken from macrophage controls or exposed to fractions FI, FII, FIII, FIV, FV obtained from TSV or IFN- $\gamma$ were assayed by adding $100 \mu \mathrm{L}$ of freshly prepared Griess reagent [25] to $100 \mu \mathrm{L}$ of the sample in 96-well plates, and then reading the absorbance at $540 \mathrm{~nm}$ after 10 minutes. Later they were compared with the absorbance curves of serial dilutions of sodium nitrate in complete culture medium. The minimum level of $\mathrm{NO}$ which was detected under the assay conditions was $1 \mathrm{nmol}$.

\section{Cytokine determination}

The levels of cytokines IL-1, IL-6, IFN- $\gamma$ in the culture supernatants were assayed using a two-site sandwich enzyme-linked immunosorbent assay (ELISA) [26]. In brief, ELISA plates were coated with $100 \mu \mathrm{L}(1 \mu \mathrm{g} / \mathrm{mL})$ of the monoclonal antibodies anti-IL- $1 \alpha$, anti-IL- $1 \beta$, antiIL-6, or anti-IFN- $\gamma$ in $0.1 \mathrm{M}$ sodium carbonate buffer $(\mathrm{pH}$ 8.2) and incubated for 6 hours at room temperature. The wells were then washed with $0.1 \%$ phosphate-buffered saline (PBS/Tween-20) and blocked with $100 \mu \mathrm{L}$ of $10 \%$ FCS in PBS for 2 hours at room temperature. After washing, duplicate supernatant macrophage culture samples of $50 \mu \mathrm{L}$ were added to each well. After 18 hours of incubation at $4^{\circ} \mathrm{C}$, the wells were washed and incubated with $100 \mu \mathrm{L}(2 \mu \mathrm{g} / \mathrm{mL})$ of the biotinylated monoclonal antibodies anti-IL- $\alpha$, anti-IL- $1 \beta$, anti-IL- 6 , or anti-IFN- $\gamma$ as second antibodies for 45 minutes at room temperature. After a final wash, the reaction was developed by the addition of OPD to each well. Optical densities were measured at $405 \mathrm{~nm}$ in a microplate reader. The cytokine content of each sample was read from a standard curve established with the appropriate recombinant cytokine (expressed in $\mathrm{ng} / \mathrm{mL}$ ). The minimum levels of each cytokine detectable in the conditions of the assays were 0.78, 2.9, and $0.05 \mathrm{ng} / \mathrm{mL}$ for IL-6, IFN- $\gamma$, and IL-1, respectively.

To measure the cytotoxicity of TNF present in the supernatants taken from the macrophages, a standard assay with L929 cells, a fibroblast continuous cell line, was used

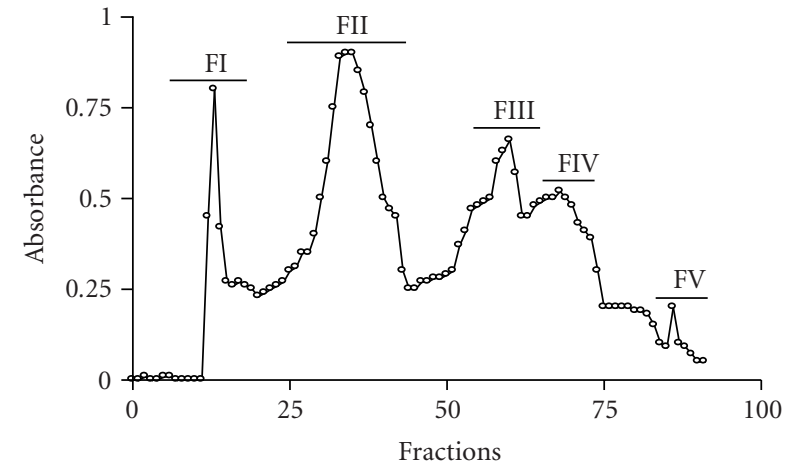

Figure 1. Purification of TSV. Fifty mg of TSV was extracted with $2 \mathrm{~mL}$ of ammonium bicarbonate solution $20 \mathrm{mM}$, and $46 \mathrm{mg}$ of the soluble venom was applied to Sephadex G-50 column $(80 \mathrm{~cm} \times 0.4 \mathrm{~cm})$ and eluted with $20 \mathrm{mM}$ ammonium bicarbonate solution, $\mathrm{pH}$ 7.4. The fractions were collected using an automatic collector and pooled according to the absorbance profile at $280 \mathrm{~nm}$ and assayed for toxicity.

as described previously by Ruff and Gifford [27]. The cytotoxicity percentage was calculated as follows: $\left(\mathrm{A}_{\text {control }}-\right.$ $\left.\mathrm{A}_{\text {sample }} / \mathrm{A}_{\text {control }}\right) \times 100$.

\section{Statistical analyses}

Data are expressed as the mean \pm standard deviation. Statistical analyses were performed by Student " $t$ test" and the level of significance was set at $P<.005$.

\section{RESULTS}

\section{Chromatography}

The TSV venom was purified by gel filtration chromatography. Figure 1 shows the chromatography profiles of components from the venom of $T$ serrulatus. The fractions FII, FIII, and FIV represent the most abundant toxins of TSV, corresponding to $31.4 \%, 21.3 \%$, and $24.4 \%$ of the whole soluble venom. PAGE confirmed the homogeneity of this component (results not shown). All fractions obtained were tested on mice and macrophage cultures.

\section{Lethal, toxic, or nontoxic doses variations}

Symptoms. Victims of scorpion envenoming suffer a variety of pathologies such as irritability, hyperthermia, vomiting, tremor, and convulsion. To determine the symptoms, groups of BALB/c female mice weighing between 18-20 g were IP injected with different doses of the fractions and were observed at various time intervals (results not shown). Three designations were used to characterize the degree of intoxication: "lethal" meaning that the animal showed some, if not all, of the symptoms described and died within 24 hours after injection. When FII and/or FIII were applied at a concentration corresponding to $105 \mu \mathrm{g}$, they had a lethal effect on mice. In contrast, these same fractions applied at a concentration of $50 \mu \mathrm{g}$ for the assay per mouse demonstrated 

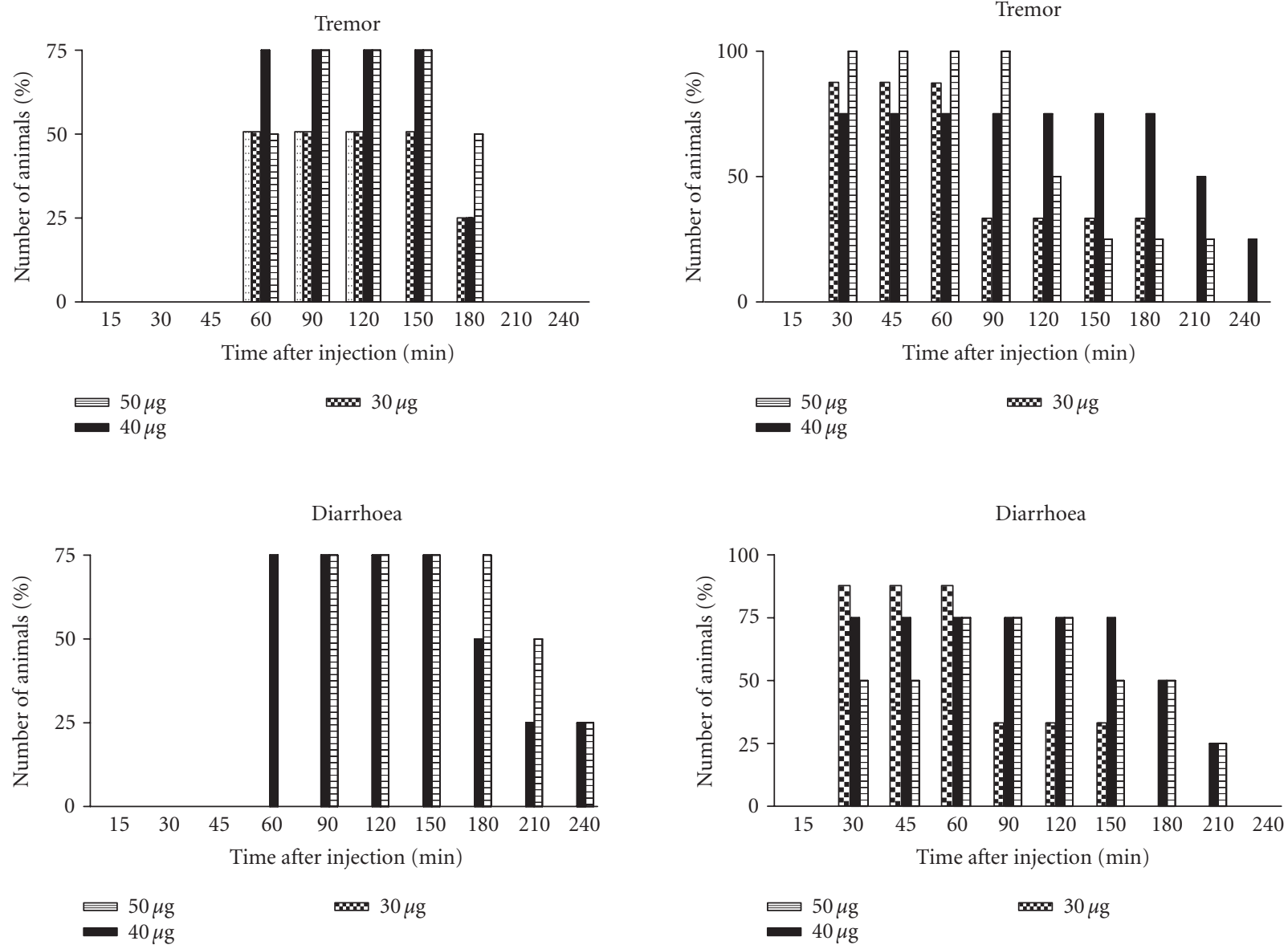

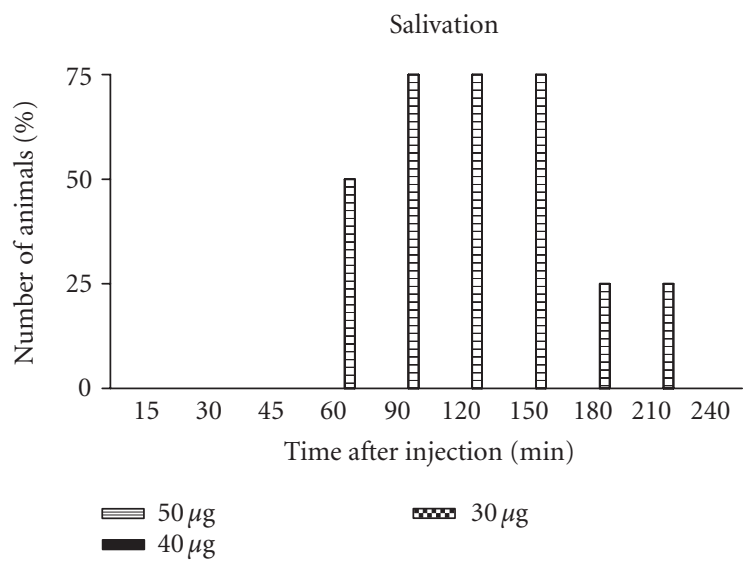

(a) Fraction FII.

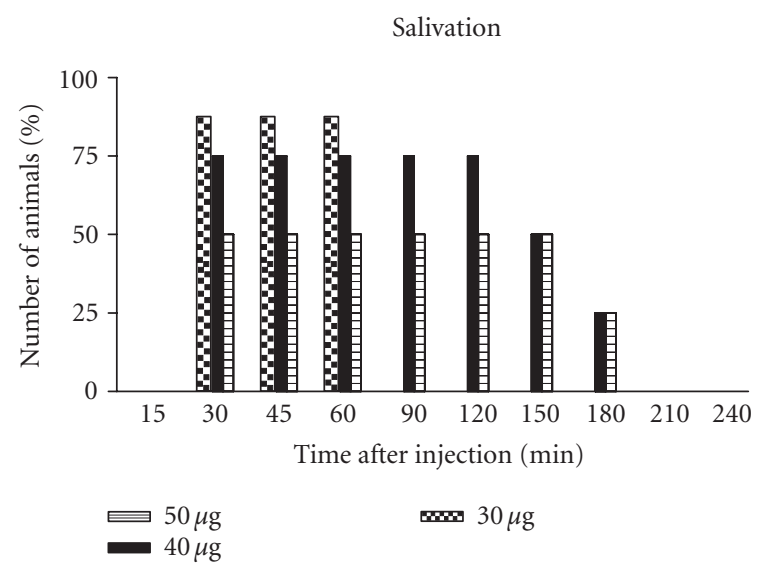

(b) Fraction FIII.

Figure 2. Symptoms. Groups of female mice from the BALB/c strain, 18-20 g of body weight, were injected IP with different doses of fractions (FII or FIII). At different time intervals, the specific signs were observed. Each point represents the percentage number of animals with symptoms.

a toxic effect. "Toxic" means that the mouse showed some of the symptoms described but survived (Figure 2). The FI, FIV, and FV applied at a concentration of $50 \mu \mathrm{g}$ for the assay per mouse showed nontoxic effects, mean- ing that the mouse demonstrated the same behaviour as after injection with saline solution (data not shown). Tremor started to appear in some animals 60 and 30 minutes after injection with FII and FIII, respectively. 


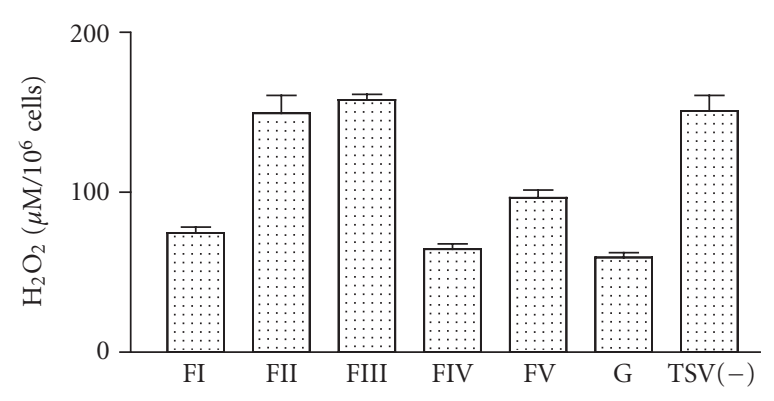

(a)

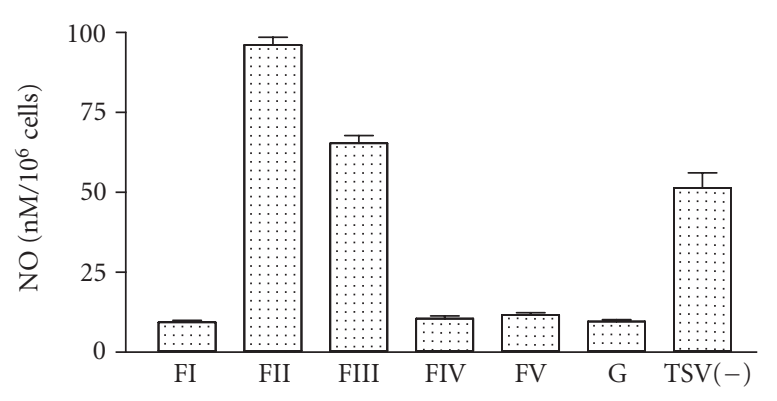

(b)

Figure 3. $\mathrm{H}_{2} \mathrm{O}_{2}$ and $\mathrm{NO}$ production. Peritoneal macrophages were obtained and stimulated in vitro with $50 \mu \mathrm{g}$ of each fraction obtained from TSV, as described in "materials and methods." The activation of the cultured peritoneal macrophages was determined by measuring the oxygen intermediate metabolites $\left(\mathrm{H}_{2} \mathrm{O}_{2}\right)$. NO levels were detected by the Griess colorimetric reaction. Each point represents the mean \pm standard deviation value of samples from five experiments carried out on different groups each consisting of five mice. Statistical differences between the treatments were $(P>.001)$.

In groups of mice injected with FII, diarrhoea started to appear in some animals between 60-90 minutes after injection with 40 and/or $50 \mu$ g per mouse, respectively (Figure 2). In contrast, in groups of mice injected with 30,40 , or $50 \mu \mathrm{g} /$ mouse of FIII, these symptoms were observed 30 minutes after injection (Figure 2). With respect to salivation, this symptom appeared 60 minutes after injection and progressed for 150 minutes after injection with $50 \mu \mathrm{g} /$ mouse of FII (Figure 2). Salivation was also observed in groups of animals injected with 30,40 , and $50 \mu \mathrm{g}$ of FIII (Figure 2).

\section{Effect of fractions from TSV on in vitro $\mathrm{H}_{2} \mathrm{O}_{2}$, $\mathrm{NO}$, and cytokine production}

To determine cytokine production, groups of mice were sacrificed and the macrophages, which were collected by peritoneal lavage, were exposed in vitro to varying amounts of different fractions obtained from TSV. The first issue to be addressed was the determination of the amounts of different fractions obtained from TSV. For this purpose, four different concentrations, ranging between $25-150 \mu \mathrm{g}$ of the various fractions were used (results not shown). All fractions were capable of stimulating cytokine, $\mathrm{NO}$ and $\mathrm{H}_{2} \mathrm{O}_{2}$ production, in a way which was dose-dependent (results not shown). Thus, in subsequent cell experiments, $50 \mu \mathrm{g}$ was used since this concentration was efficient for all fractions.

The levels of $\mathrm{H}_{2} \mathrm{O}_{2}$ observed in macrophages groups stimulated for 48 hours with FII and FIII were similar to those observed for TSV $(-)$ (Figure 3a). The levels of NO in groups of macrophages exposed to FII were significantly higher when compared with those obtained from cultures exposed to TSV $(-)$ and/or other fractions $(P>$ .001) (Figure 3b). Interestingly the nontoxic fractions had significantly lower levels of $\mathrm{H}_{2} \mathrm{O}_{2}$ and $\mathrm{NO}$ when compared to those obtained from FII, FIII, and/or TSV $(-)$ (Figures $3 \mathrm{a}$ and $3 \mathrm{~b})$.

The in vitro exposure of macrophages to FII resulted in the production of higher levels of IL- $1 \alpha$
(Figure 4). Similar levels of IL-1 $\beta$ were observed in groups of macrophages exposed to FII, FIII, FV, and TSV $(-)$ (Figure 4). The highest levels of IL-6 were observed in groups of macrophages exposed in vitro to $\mathrm{TSV}(-)$ or FII were observed $(P>.001)$ (Figure 4$)$. The high levels of IFN- $\gamma$ in groups of macrophages exposed in vitro to TSV $(-)$, FII, and FV were observed (Figure 4). Interestingly, only macrophages groups exposed to FII demonstrated TNF production (Figure 4).

\section{Kinetics of $\mathrm{H}_{2} \mathrm{O}_{2}, \mathrm{NO}$, and cytokine production}

To determine the kinetics of $\mathrm{H}_{2} \mathrm{O}_{2}, \mathrm{NO}$, and cytokine production, groups of mice were sacrificed and the macrophages, which were collected by peritoneal lavage, were exposed in vitro to $50 \mu \mathrm{g}$ of each fraction obtained. The in vitro exposition of macrophages to FII, FIII, or TSV $(-)$ resulted in $\mathrm{H}_{2} \mathrm{O}_{2}$ production (Figure 5). The maximum production of $\mathrm{H}_{2} \mathrm{O}_{2}$ was detected in cultures stimulated for 48 hours, decreasing thereafter (Figure 5). Similar levels of $\mathrm{H}_{2} \mathrm{O}_{2}$ were observed in groups of macrophages stimulated in vitro with FII, FIII, or TSV $(-)$ (Figure 5).

The levels of NO increased for up to 72 hours for all macrophage groups exposed in vitro to FII, FIII, or TSV (-) decreasing thereafter (Figure 5). The levels of $\mathrm{NO}$ in groups of macrophages stimulated with FII were significantly higher when compared with those obtained from FIII and TSV $(-)$ cultures $(P>.001)$ (Figure 5).

We noted a significant difference in IL-1 production between fractions obtained from TSV (Figure 6). The maximum levels of IL- $1 \alpha$ and IL- $1 \beta$ were observed in cultures stimulated for 12 hours (Figure 6). The levels of IL$1 \alpha$ in groups of macrophages stimulated with FII were significantly higher when compared with those obtained in FIII and TSV $(-)$ cultures $(P>.001)$ (Figure 6). Twelve hours after treatment, macrophages exposed to FII secreted twice as much IL- $1 \alpha$ compared to macrophages infected with TSV $(-)$ or FIII $(P>.001)$. With respect to IL- $1 \beta$ production similar levels were observed among 

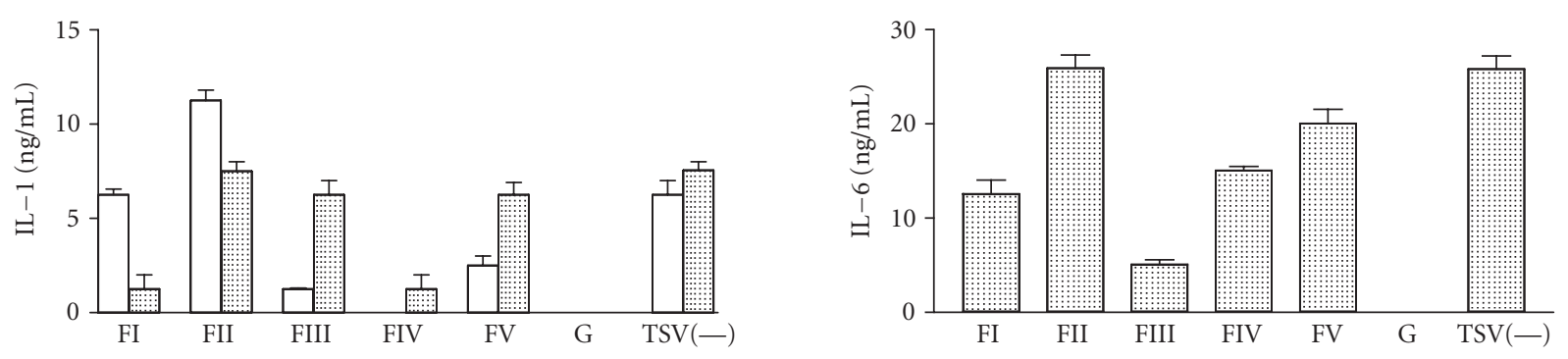

$$
\begin{array}{ll}
\rightleftarrows \mathrm{IL}-1 \alpha \\
\mathrm{IL}-1 \beta
\end{array}
$$

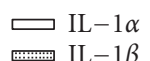
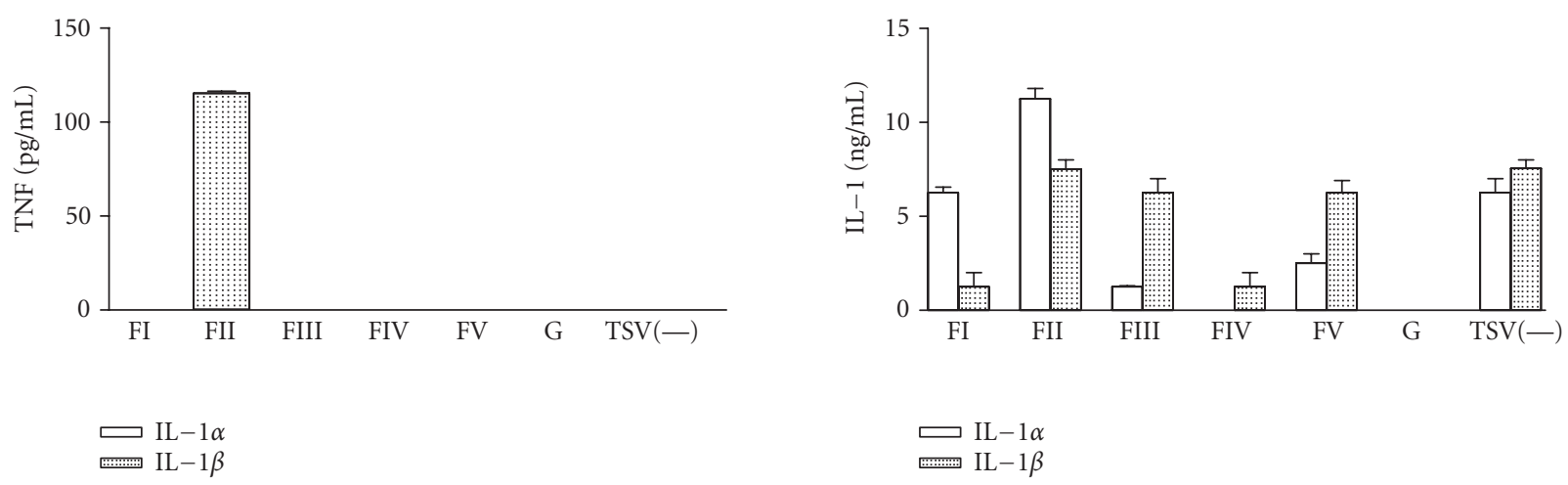

FIgURE 4. Cytokine released by peritoneal macrophages from BALB/c mice. Peritoneal macrophages were obtained and stimulated in vitro with $50 \mu \mathrm{g}$ of the various fractions obtained from TSV, as described in "materials and methods." The levels of IL-1 were determined after 12 hours, for IL- 6 after 24 hours and for IFN- $\gamma$ after 72 hours. They were assayed by ELISA assay using antibodies as the probe. TNF levels were determined by a standard assay with L929 cells. Each point represents the mean value of samples from five experiments \pm standard deviation among different groups consisting of five mice. Statistical differences between the treatments were $(P>.001)$.
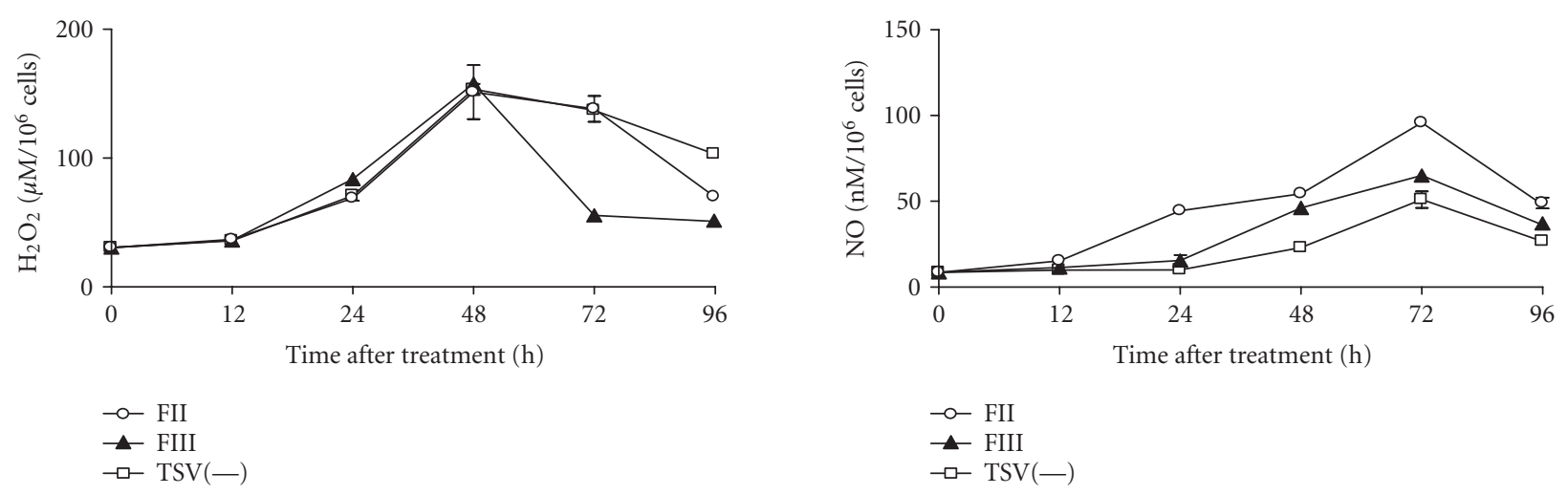

Figure 5. The kinetic of activation and NO production. Peritoneal macrophages were obtained and stimulated in vitro with $50 \mu \mathrm{g}$ of FII, FIII, and TSV (-) obtained as described in "materials and methods." The activation of peritoneal macrophages was determined by measuring the oxygen intermediate metabolites $\left(\mathrm{H}_{2} \mathrm{O}_{2}\right)$. NO levels were detected by the Griess colorimetric reaction. Each point represents the mean \pm standard deviation value of samples from five experiments in different groups consisting of five mice. Statistical differences between the treatments were $(P>.001)$.

all groups of macrophages that were stimulated (Figure $6)$. As shown in Figure 6, the maximum levels of IL6 were observed in all cultures stimulated for 24 hours.
The levels of IL-6 in groups of macrophages exposed to FII and TSV $(-)$ were significantly higher when compared with those obtained in FIII cultures $(P>.001)$ 

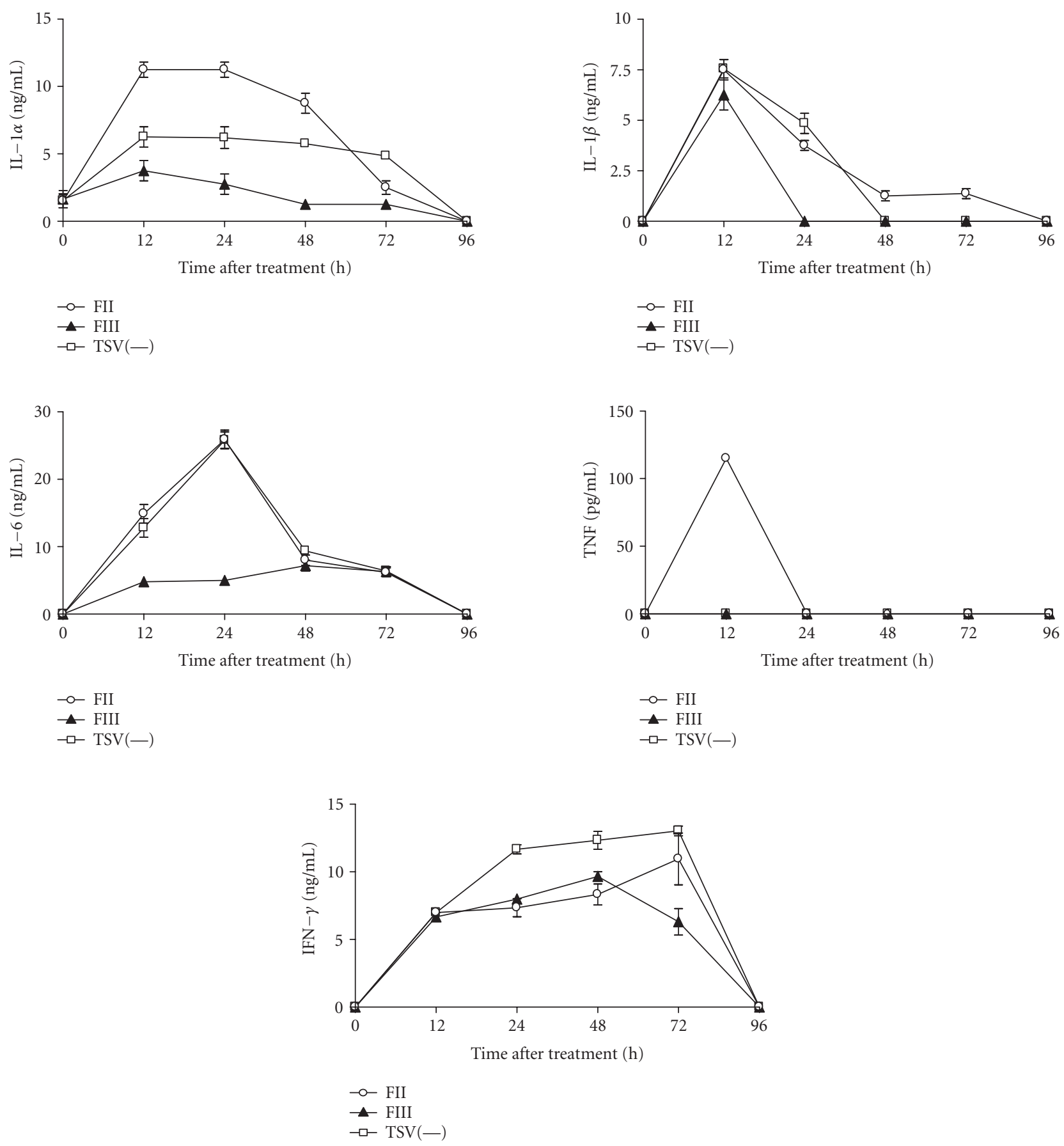

FIGURE 6. The kinetic of cytokines released by peritoneal macrophages from BALB/c mice. Peritoneal macrophages were obtained and stimulated in vitro with $50 \mu \mathrm{g}$ of TSV(-), FII, and FIII obtained from TSV as described in "materials and methods." IL-1, IL-6, and IFN- $\gamma$ were assayed by ELISA assay using antibodies as the probe. TNF levels were determined by a standard assay with L929 cells. Each point represents the mean value of samples from five experiments \pm standard deviation in different groups consisting of five mice. Statistical differences between the treatments were $(P>.001)$.

(Figure 6). For groups of macrophages exposed to FII and TSV $(-)$ levels of IFN- $\gamma$ started to appear after 12 hours for all groups, increasing for up to 72 hours and decreasing thereafter. In the case of groups of macrophages exposed to FII and TSV(-). In the case the groups of macrophages stimulated with FIII, the high levels of IFN$\gamma$ were observed after 48 hours (Figure 6). Under the conditions used in this study, TNF production from murine peritoneal macrophages was not observed after treatment with TSV(-) and FIII. In contrast, high levels of TNF 
were observed for groups of macrophages exposed to FII for 12 hours (Figure 6).

\section{Effect of exogenous cytokine on macrophages stimulated with FII, FIII, or TSV(-)}

To verify whether exogenous cytokines, such as IFN- $\gamma$, showed an effect on macrophages treated with TSV $(-)$, FII, or FIII, the levels of $\mathrm{H}_{2} \mathrm{O}_{2}$ and $\mathrm{NO}$ were determined. The addition of IFN- $\gamma$ to the culture medium did not alter $\mathrm{H}_{2} \mathrm{O}_{2}$ released by the fractions or the TSV $(-)$-activated macrophages. In contrast, the addition of IFN- $\gamma$ to the culture medium significantly altered the amount of significance $(P>.01)$, NO secretion by the FII-activated macrophages (Figure 7).

\section{DISCUSSION}

Scorpion venom consists of complex mixtures of several toxins that exhibit various biological activities. It has already been shown that human victims stung by scorpion or experimentally injected animals may exhibit signs and symptoms which involve the central nervous system, stimulation of the autonomic system, and, occasionally, respiratory and heart failure, and even death [28, 29]. Various factors can contribute to the manifestation of specific signs and symptoms as reactions to stings with respect the scorpion venom toxicity which may vary [30]. However it has been demonstrated that other factors may also be considered as clinical signs such as the age or size of the victims, for example, children are normally more severely affected, the site of the injection, and the individual's vulnerability to venom $[28,29,31]$.

Data presented in this report reveal the immunomodulating property of TSV: (1) the induction of cytokines by peritoneal macrophages and (2) the induction of NO secretion and enhancement of $\mathrm{H}_{2} \mathrm{O}_{2}$. The experiments were designed in order to know which fraction is responsible for the immunomodulating effect; and subsequently several strategies for applying injections were tested. With respect to the specific signals, the dose administered, the severity of envenoming, and the cytokines and NO production were studied and discussed.

The rapid absorption and distribution of scorpion venom toxins indicate that scorpion envenoming is an extreme emergency case. Specific signs and symptoms are usually manifested very soon after envenomating, and develop into systemic inflammatory manifestations and organ failure. Increasing evidence from animal studies as well as clinical experience show that the involvement of the inflammatory cascade and release of cytokines play a major role in the pathogenesis of many envenoming syndromes.

The quality of the immune response is reflected in the production of immunoglobulin isotypes, the different Tcell subsets activated, and the cytokines synthesized. The characterization of the roles of specific cytokines generated during an immune response has been impeded be- cause of the complexity of the cytokine system, not only because of the pleiotropic effects of individual cytokines but also because of antagonistic and synergistic effects of cytokine combinations.

Severe envenomating induced in mice injected with TSV was associated with an elevation in the serum levels of various cytokines and NO. With respect to immune response, recent studies regarding the roles that cytokines may play in defending the host also indicate the importance of this aspect in the case of envenomating. Cytokines are a group of regulatory and immunomodulatory proteins involved in a number of physiological processes. As part of the characterization of the hosts reactivity to TSV (-) and/or fractions, inflammatory responses in the mouse model were investigated. Proinflammatory cytokines induce local and systemic inflammatory manifestations. The local effects include the activation of vascular endothelium, an increase in vascular permeability, and access of leukocytes to the affected tissue and their activation and local tissue destruction. The systemic manifestations include fever, the acute-phase response, and induction of a systemic shock in severe inflammatory processes. The proinflammatory cytokines such as IL-1, TNF, and IL- 6 are endogenous pyrogens, which raise the body temperature in a way which is believed to help eliminate infections $[32,33]$. Thus, IL-1 probably contributes to systemic inflammatory response in envenomated mice.

The cytokine IL-1 mainly affects inflammatory processes but also possesses various immune, degradative, and growth-promoting properties. There are two IL-1 agonistic proteins, IL- $1 \alpha$ and IL- $1 \beta$, and one antagonistic protein [34]. IL- $1 \alpha$ and IL- $1 \beta$ bind to the same receptors, and there are no significant differences in their spectrum of activities [34]. However, the processes of IL- $1 \alpha$ and IL- $1 \beta$ differ: IL- $1 \beta$ is active only as a secreted mature product, whereas IL- $1 \alpha$ is active as a precursor or membrane-associated molecule. IL- $1 \alpha$ remains cytosolic but IL- $1 \beta$ is abundantly secreted by activated macrophages and blood monocytes. Here, we show that IL- $1 \beta$ production was observed among all macrophages exposed to fractions obtained from TSV. The maximum production of IL- $1 \alpha$ was observed in cultures exposed to FII for 12 hours. In this study, TSV $(-)$ and its fractions induced elevations of IL- $1 \alpha$ and IL- $1 \beta$, which were detected by ELISA. The effect of IL- 1 production in response to TSV stimulation in vitro may be a doubleedged sword. The results presented here demonstrate that IL-1 may contribute to the symptoms of venom treatment by emphasizing the effect of other cytokines. Apparently the biological actions appear to contribute to the shock induction and other systemic alterations.

Other studies have shown that inflammatory models have indicated that proinflammatory substances and some cytokines were deeply involved in the activation of endothelial cells and leukocytes [35]. The results obtained in this study showed the effect of TSV $(-)$ and its fractions on murine peritoneal macrophages. These results are in accordance with previous studies that showed an 

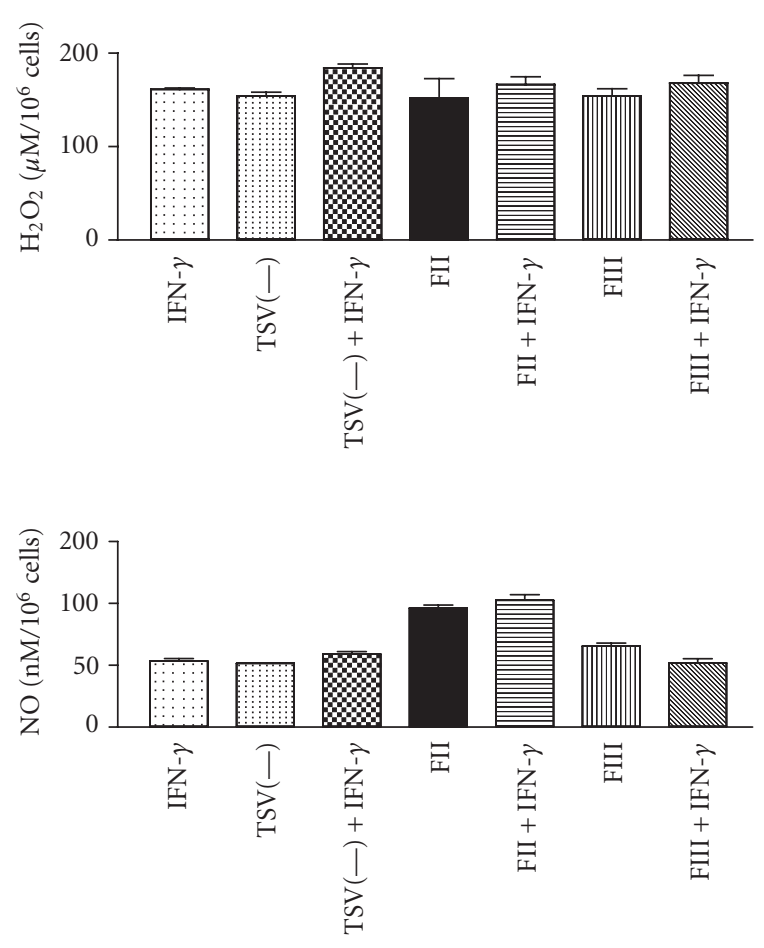

Figure 7. Comparisons of $\mathrm{H}_{2} \mathrm{O}_{2}$ and NO production after FII, FIII, TSV $(-)$, or IFN- $\gamma$ stimulation. Groups of mice were sacrificed and their peritoneal macrophages were collected. Peritoneal macrophages were stimulated in vitro with $50 \mu \mathrm{g} / \mathrm{mL}$ of FII, FIII, TSV $(-)$, IFN- $\gamma(10 \mathrm{ng} / \mathrm{mL})$, FII + IFN- $\gamma$, FIII + IFN$\gamma$, or TSV $(-)+$ IFN $-\gamma \cdot \mathrm{H}_{2} \mathrm{O}_{2}$ and NO levels were determined as described in Figure 5, at 48 and 72 hours after stimulation, respectively. Each point represents the mean \pm standard deviation value of samples from five experiments in different groups consisting of five mice.

IL-6 release from mice macrophages exposed to different venoms $[18,19,36,37]$.

Various studies have shown that TNF is a key intermediate in the over reaction on the part of the host. TNF exerts a wide spectrum of biological activities and contributes to the pathophysiology of septic shock. Under the conditions used in the present study, we observed that the effect of FII on the macrophage may alter TNF production. TNF, IL- $1 \alpha$, and IL- $1 \beta$ production peaked after 12 hours, whereas IL- 6 peaked after 24 hours. The decrease of TNF levels after 48 hours has been also observed by other authors $[38,39]$. The transient accumulation of TNF could be explained by consumption due to an autocrine process. The secretion by phagocytizing cells of proinflammatory cytokines accounts for characteristic granuloma formation. Cytokine concentrations were comparable to those detected after macrophage treatment with crude TSV. The high levels of TNF produced by macrophages following exposure to FII may suggest that this is the main factor responsible for septic shock diarrhoea observed in animal models. Together with IL-1, TNF may account for the acute-phase response symptoms such as fever and lethargy.
Thus these results show that the murine macrophages treated with fractions are stimulated to produce the proinflammatory acute-phase cytokines TNF, IL-1, and IL-6, but in nontoxic form. Such differences in the induction of these proinflammatory cytokines by macrophages in response to toxic fractions may be an important factor in the pathogenesis induced by this venom.

IFN- $\gamma$ is a key cytokine in host defences against intracellular organisms and enhances the ability of peritoneal macrophages and Kupffer cells for phagocytosis [40, 41]. These authors in $[40,41]$ indicated that the IFN- $\gamma$ may exert and participate in both beneficial and detrimental effects. The present study shows that TSV $(-)$ and its fractions are capable of stimulating murine peritoneal macrophages to release IFN- $\gamma$. Cytokines are potent powerful modulators of murine macrophage reactive oxygen intermediates such as $\mathrm{H}_{2} \mathrm{O}_{2}$ and reactive nitrogen intermediates such as NO.

The hypothesis that the TSV is capable of exerting action on macrophages was formulated by Petricevich [18]. The present study describes an experimental model designed to test the hypothesis that the fraction(s) obtained from venom could be responsible for macrophage activation. To examine this possibility, the preestablished doses of TSV $(-)$ and its fractions were added to cultured macrophages, and the activation of these cells was determined. Different amounts of TSV $(-)$ and/or fractions were used for this study (data not shown) which were capable of activating macrophages for the release of $\mathrm{H}_{2} \mathrm{O}_{2}$.

In macrophages, $\mathrm{NO}$ and other reactive nitrogen intermediates are derived from L-arginine via an enzymatic pathway controlled by an inducible NO synthase (iNOS) [42], and their synthesis is modulated by cytokines. While TNF and IFN- $\gamma$ are potent activators of iNOS, IL4 and IL-10 suppress it $[43,44,45]$. NO is known to be involved in multiple biologically important reactions. The effects of $\mathrm{NO}$ on the inflammatory response depends on the concentration. Low levels of NO appear to be antiinflammatory, while higher levels such as those produced in response to bacterial lipopolysaccharide can be proinflammatory [46]. In this study, we described the fact that TSV (-) and/or fractions FII and FIII from venom have the ability to stimulate macrophages to produce NO and may exert a modulatory effect on NO levels and thus on the host inflammatory response. This may result in the development of symptomatic or asymptomatic injections, depending on the relative activities.

The effects of TSV $(-)$ and fractions on $\mathrm{H}_{2} \mathrm{O}_{2}$ and NO production were compared with those caused by IFN$\gamma$ stimulation. Peritoneal macrophages stimulated with TSV (-) and fractions FI, FIII, FIV, and FV, fail to produce TNF either alone or in combination with IFN- $\gamma$ as a costimulus. The levels of $\mathrm{H}_{2} \mathrm{O}_{2}$ were modest and increased for groups of macrophages stimulated with TSV (-) and/or FII or FIII combined with IFN- $\gamma$. In contrast, in groups of peritoneal macrophages stimulated with FII combined with IFN- $\gamma$, a significant increase in levels of NO was observed. These results suggest that one 
compound or a synergism of several TSV $(-)$ constituents presented immunomodulatory activity through the activation of macrophage function with consequent oxygen.

\section{REFERENCES}

[1] Freire-Maia L, Campos JA. Pathophysiology and treatment of scorpion poisoning. In: Ownby CL, Odell GV, eds. Natural Toxins: Characterization, Pharmacology and Therapeutics. Oxford: Pergamon Press; 1989:139-159.

[2] Bucaretchi F, Baracat EC, Nogueira RJ, et al. A comparative study of severe scorpion envenomation in children caused by Tityus bahiensis and Tityus serrulatus. Rev Inst Med Trop São Paulo. 1995;37(4):331336.

[3] Freire-Maia L, Campos JA, Amaral CF. Approaches to the treatment of scorpion envenoming. Toxicon. 1994;32(9):1009-1014.

[4] Garcia-Calvo M, Leonard RJ, Novick J, et al. Purification, characterization, and biosynthesis of margatoxin, a component of Centruroides margaritatus venom that selectively inhibits voltagedependent potassium channels. J Biol Chem. 1993;268(25):18866-18874.

[5] Werkman TR, Gustafson TA, Rogowski RS, Blaustein MP, Rogawski MA. Tityustoxin-K alpha, a structurally novel and highly potent $\mathrm{K}+$ channel peptide toxin, interacts with the alpha-dendrotoxin binding site on the cloned Kv1.2 K+ channel. Mol Pharmacol. 1993;44(2):430-436.

[6] Stampe P, Kolmakova-Partensky L, Miller C. Intimations of $\mathrm{K}+$ channel structure from a complete functional map of the molecular surface of charybdotoxin. Biochemistry. 1994;33(2):443-450.

[7] Andrade SP, Santos RA, Beraldo WT. Comparative study of the action of purified scorpion toxin (Tityustoxin) on the submandibular and parotid glands of the rat. Toxicon. 1981;19(2):255-261.

[8] Cunha-Melo JR, Gonzaga HM, Alzamora F, FreireMaia L. Effects of purified scorpion toxin (Tityustoxin) on gastric secretion in the rat. Toxicon. 1983;21(6):843-848.

[9] Novaes G, Cabral AP, de Falco CN, de Queiroz AC. Acute pancreatitis induced by scorpion toxin, Tityustoxin. Histopathological study in rats. Arq Gastroenterol. 1989;26(1-2):9-12.

[10] Cunha-Melo JR, Toppa NH, Martins P, Colares CN, Castro YS, Freire-Maia L. Acute gastric mucosal injury induced by toxins from Tityus serrulatus scorpion venom: a novel experimental model in the rat. Toxicon. 1991;29(11):1395-1401.

[11] Lima MR, dos Santos MC, Tambourgi DV, Marques T, da Silva WD, Kipnis T. Susceptibility of different strains of mice to South American rattlesnake (Crotalus durissus terrificus) venom: correlation be- tween lethal effect and creatine kinase release. Toxicon. 1991;29(6):783-786.

[12] Meki AR, Mohey El-Dean ZM. Serum interleukin1 beta, interleukin-6, nitric oxide and alpha1antitrypsin in scorpion envenomed children. Toxicon. 1998;36(12):1851-1859.

[13] Chippaux JP, Williams V, White J. Snake venom variability: methods of study, results and interpretation. Toxicon. 1991;29(11):1279-1303.

[14] Coffman RL, Mosmann TR. CD4+ T-cell subsets: regulation of differentiation and function. Res Immunol. 1991;142(1):7-9.

[15] Stein M, Gordon S. Regulation of tumor necrosis factor (TNF) release by murine peritoneal macrophages: role of cell stimulation and specific phagocytic plasma membrane receptors. Eur J Immunol. 1991;21(2):431-437.

[16] Van der Meide PH, Schellekens H. Cytokines and the immune response. Biotherapy. 1996;8(3-4):243-249.

[17] Jo T, Terada N, Takauchi Y, et al. Cytotoxic actions of cytokines on cultured mouse luteal cells are independent of nitric oxide. J Steroid Biochem Mol Biol. 1995;55(3-4):291-296.

[18] Petricevich VL. Effect of Tityus serrulatus venom on cytokine production and the activity of murine macrophages. Mediators Inflamm. 2002;11(1):2331.

[19] Barros SF, Friedlanskaia I, Petricevich VL, Kipnis TL. Local inflammation, lethality and cytokine release in mice injected with Bothrops atrox venom. Mediators Inflamm. 1998;7(5):339-346.

[20] Bucherl W. Biology and venoms of the most important South American spiders of the genera Phoneutria, Loxosceles, Lycosa, and Latrodectus. Am Zool. 1969;9(1):157-159.

[21] International Society on Toxicology. Toxicon. 1992;30:1-12.

[22] Cohn ZA, Benson B. The differentiation of mononuclear phagocytes. Morphology, cytochemistry, and biochemistry. J Exp Med. 1965;121:153-170.

[23] Johansson S, Rubin K, Hook M, Ahlgren T, Seljelid R. In vitro biosynthesis of cold insoluble globulin (fibronectin) by mouse peritoneal macrophages. FEBS Lett. 1979;105(2):313-316.

[24] Pick E, Mizel D. Rapid microassays for the measurement of superoxide and hydrogen peroxide production by macrophages in culture using an automatic enzyme immunoassay reader. I Immunol Methods. 1981;46(2):211-226.

[25] Keller R, Keist R, Wechsler A, Leist TP, van der Meide $\mathrm{PH}$. Mechanisms of macrophage-mediated tumor cell killing: a comparative analysis of the roles of reactive nitrogen intermediates and tumor necrosis factor. Int J Cancer. 1990;46(4):682-686.

[26] Schumaker JR, O'Garra A, Schrader P. Characterization of monoclonal antibodies to mouse interleukin5 and development of mouse and human IL-5 ELISA assay. J Immunol. 1988;141:1576-1581. 
[27] Ruff MR, Gifford GE. Purification and physicochemical characterization of rabbit tumor necrosis factor. J Immunol. 1980;125(4):1671-1677.

[28] Ismail M. The scorpion envenoming syndrome. Toxicon. 1995;33(7):825-858.

[29] Sofer S. Scorpion envenomation. Intensive Care Med. 1995;21(8):626-628.

[30] Kalapothakis E, Chavez-Olortegui C. Venom variability among several Tityus serrulatus specimens. Toxicon. 1997;35(10):1523-1529.

[31] Hoffman D. Insect venom allergy, immunology, and immunotherapy. In: Tu, AT, ed. Handbook of Neural Toxins: Insect Poisons, Allergens, and Other Intervertebrate Venoms. Vol.2, New York, NY: M. Dekker; 1984:187-224.

[32] Akira S, Hirano T, Taga T, Kishimoto T. Biology of multifunctional cytokines: IL 6 and related molecules (IL 1 and TNF). FASEB J. 1990;4(11):2860-2867.

[33] Baumann H, Gauldie J. The acute phase response. Immunol Today. 1994;15(2):74-80.

[34] Dinarello CA. Biologic basis for interleukin-1 in disease. Blood. 1996;87(6):2095-2147.

[35] Albelda SM, Smith CW, Ward PA. Adhesion molecules and inflammatory injury. FASEB J. 1994;8(8):504-512.

[36] Barraviera B, Lomonte B, Tarkowski A, Hanson LA, Meira DA. Acute-phase reactions, including Cytokines, in patients bitten by Bothrops and Crotalus snakes in Brazil. J Venom Anim Toxins. 1995;1(1):1122.

[37] Lomonte B, Tarkowski A, Hanson LA. Host response to Bothrops asper snake venom. Analysis of edema formation, inflammatory cells, and cytokine release in a mouse model. Inflammation. 1993;17(2):93105.

[38] Caron E, Peyrard T, Kohler S, Cabane S, Liautard JP, Dornand J. Live Brucella spp. fail to induce tumor necrosis factor alpha excretion upon infection of U937-derived phagocytes. Infect Immun. 1994;62(12):5267-5274.

[39] Goodrum KJ, Dieksheide J, Yoder BJ. Tumor necrosis factor alpha acts as an autocrine second signal with gamma interferon to induce nitric oxide in group B streptococcus-treated macrophages. Infect Immun. 1995;63(9):3715-3717.

[40] Kaufmann SH. Immunity to intracellular bacteria. Annu Rev Immunol. 1993;11:129-163.

[41] Cross A, Asher L, Seguin M, et al. The importance of a lipopolysaccharide-initiated, cytokinemediated host defense mechanism in mice against extraintestinally invasive Escherichia coli. J Clin Invest. 1995;96(2):676-686.

[42] Nathan C, Xie QW. Nitric oxide synthases: roles, tolls, and controls. Cell. 1994;78(6):915-918.

[43] Flesch IE, Kaufmann SH. Role of cytokines in tuberculosis. Immunobiology. 1993;189(3-4):316-339.

[44] Gazzinelli RT, Oswald IP, Hieny S, James SL, Sher
A. The microbicidal activity of interferon-gammatreated macrophages against Trypanosoma cruzi involves an L-arginine-dependent, nitrogen oxidemediated mechanism inhibitable by interleukin-10 and transforming growth factor-beta. Eur J Immunol. 1992;22(10):2501-2506.

[45] Oswald IP, Gazzinelli RT, Sher A, James SL. IL10 synergizes with IL-4 and transforming growth factor-beta to inhibit macrophage cytotoxic activity. J Immunol. 1992;148(11):3578-3582.

[46] Grisham MB, Jourd'Heuil D, Wink DA. Nitric oxide. I. Physiological chemistry of nitric oxide and its metabolites: implications in inflammation. Am J Physiol. 1999;276(2 pt 1):G315-G321. 


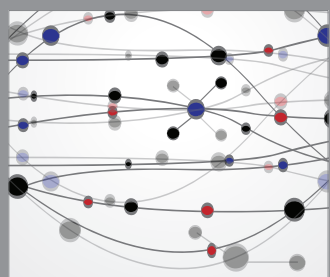

The Scientific World Journal
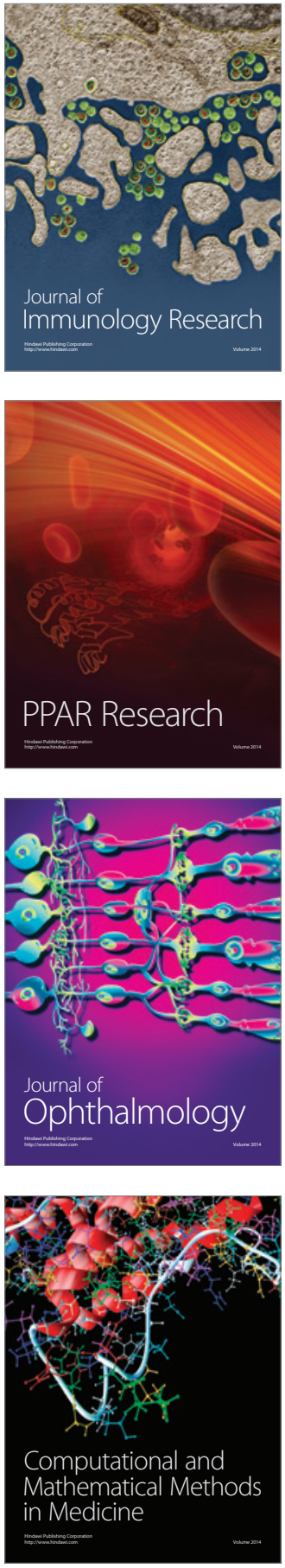

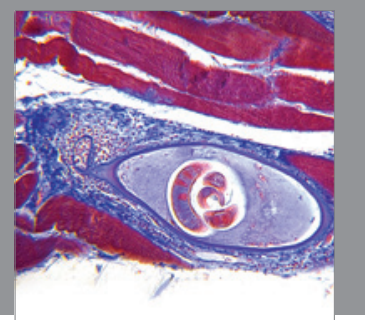

Gastroenterology

Research and Practice
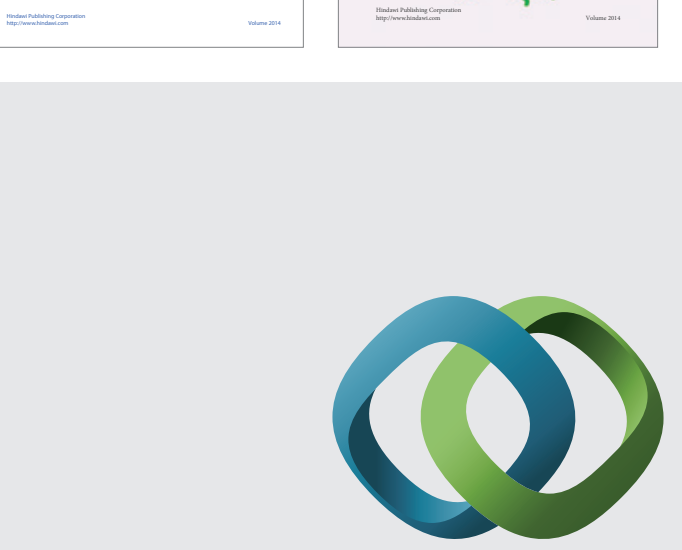

\section{Hindawi}

Submit your manuscripts at

http://www.hindawi.com
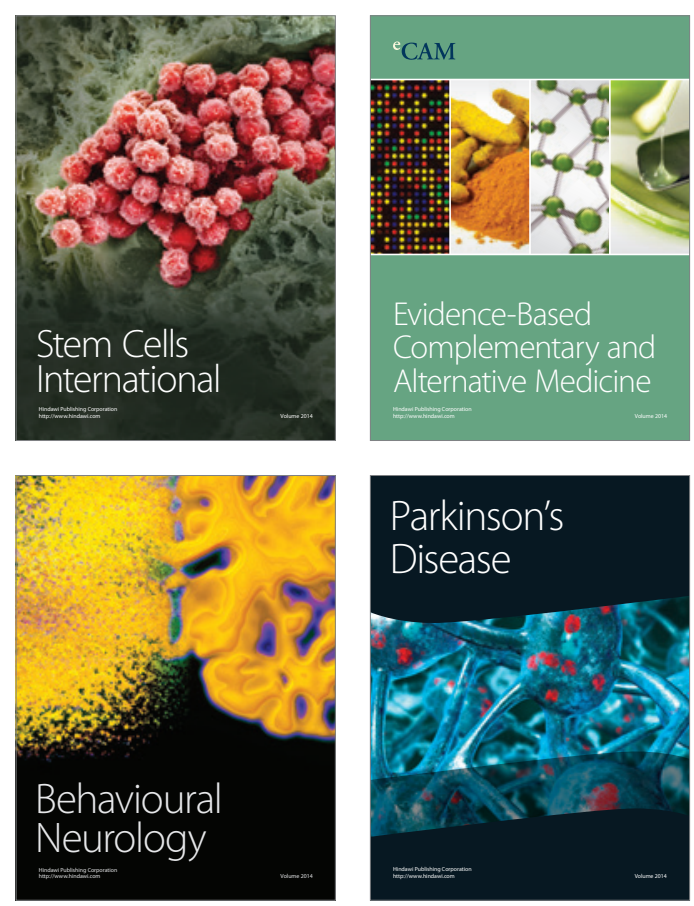

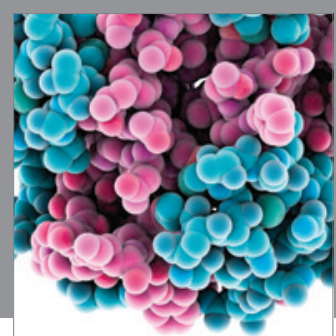

Journal of
Diabetes Research

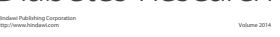

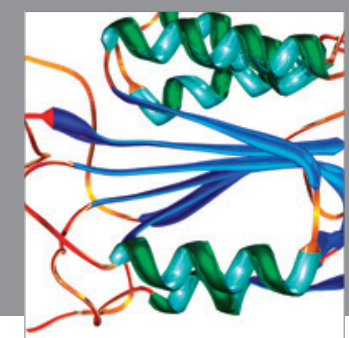

Disease Markers
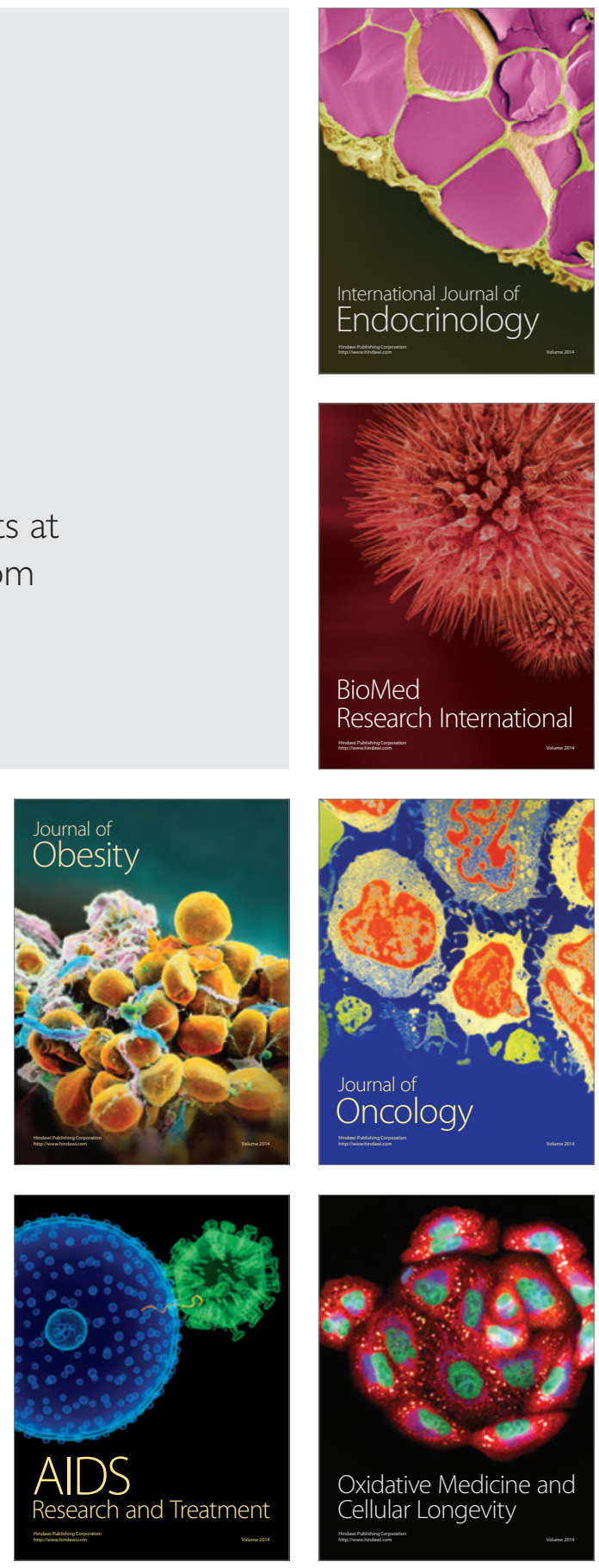